\title{
A Discussion on the Characteristics of the Internet Platform Economy in the Information Age
}

\author{
Xiaoming Qiao \\ Journal Editorial Department, Yunnan Normal University, Kunming City, \\ Yunnan Province, 650092, China
}

\begin{abstract}
In the information age, the Internet platform economy has become the most active part of the new economy. Internet platform economy presents characteristics of hierarchy, zero-cost replication, division of labor and cooperation, openness and externality. To profoundly grasp the characteristics of the Internet platform economy will help enterprises to plan market competition strategy and help the government to formulate scientific and rational industrial development policies. Besides, it will promote the mass innovation and transformation development of the entire social economy.

Keywords: Information age; Internet platform economy; Sharing economy; Hierarchy; Division of labor and cooperation
\end{abstract}

\section{Introduction}

With the acceleration of information technology innovation and the popularity of the Internet application, the Internet platform economy develops rapidly. More and more Internet platform-based enterprises have emerged in large numbers and this gives birth to the development tide of the Internet platform economy. The rapid development of the Internet platform economy has far-reaching impact on the social economy[1]. The deep study of the characteristics of the Internet platform economy will help enterprises to plan market competition strategy and help the government to formulate scientific and rational industrial development policies. Besides, it will promote the mass innovation and transformation 
development of the entire social economy. The Internet platform economy is a bilateral market and its characteristics include hierarchy, openness, zero cost replication, cooperation and mutual benefits and crossed network externality[2].

\section{Hierarchy}

The structure of the Internet platform economy is hierarchical. From the characteristics of the structure of the Internet platform economy, the Internet platform economy is complex, which consists of multiple subjects with professional division and close cooperation between them. The collaboration and division of labor between these subjects forms professional functions with different levels gradually. Ultimately, this evolves into a clear hierarchical economic structure. The Internet platform economy can be divided into the base layer, platform layer, application layer and user layer from bottom to top.

\section{Replication with Zero Cost}

Zero cost replication is precisely the profound mystery of the rapid growth of the Internet platform economy and the charm of the Internet platform economy. Taking Taobao as an example, the construction of the e-commerce platform just needs limited fixed costs, but shops on the e-commerce platform can be copied infinitely with zero cost. As long as the shop applies an account, Taobao platform can open a shop with zero cost[3]. The businesses use their own resources to sell featured goods and services. At present, Taobao platform has tens of millions of shops. No matter how many shops are added on the platform, the cost of each additional store can be ignored. It is unthinkable for traditional retail sector to open shops with zero cost. In the traditional commercial real estate field, site resources are limited and $60 \%$ of the cost comes from the shop rent, which means that each additional shop will need to bear relatively high cost. For another example, there are more than 500 million WeChat accounts, but Tencent still can allow new users to register with zero cost.

\section{Openness}

The Internet platform economy is open. Internet platform open their own resources based on the provision of basic services, so that more third-party entities can participate in the ecosystem of the Internet platform to provide various applications or services. As the third-party service accesses the Internet platform, it enhances service capabilities of the Internet platform and makes daily activities of the Internet platform active, which brings more users to the Internet platform. The open Internet platform accommodates a wide range of service subjects and each service subject provides a unique product or service. Besides, 
each user also has personalized needs, so that these subjects can connect with each other and help each other to realize win-win result and their value[4].

In the context of the open Internet platform economy, the competitiveness of the Internet platform business has not depended on the size and brand of the original enterprise, but it is decided by the open Internet platform, integration of resources ability and capacity to meet user needs rapidly. For example, Taobao implements the strategy of the open Internet platform, which not only absorbs tens of thousands of network resources, but also integrates the express logistics enterprises, shop design, consulting services, models and other resources. This constitutes a coordinated and interactive business ecosystem. Apple, Google, Facebook and other international giants have also built an open platform for cooperation and mutual benefits. Google and Facebook have 5 billion API application requests every day. Twitter has 3 billion API application requests every day, which accounts for $75 \%$ of its total traffic. For another example, the cooperative model of Apple App Store which stipulates that the two parties burden the profit by 3:7 ratio attracts a large number of developers to develop new applications. This model not only brings revenues to developers, but also enriches platform applications, which attracts more users.

\section{Cooperation and Mutual Benefits}

Internet platform economy has a major feature that subjects on the Internet platform carry out professional labor division to achieve cooperation and mutual benefits. The emergence of the Internet turns the world-wide cooperation without the limitations of time and space into reality. In the future, it will become an inevitable trend to carry out professional labor division and social cooperation which relies on the Internet platform and the big data, and takes users' needs as the orientation[5]. The Internet platform is a collection of a wide range of specialized resources and any one of the platform subjects can find corresponding resources, provide services, or make requests. Subjects on the platform can cooperate with each other, complement each other with their own advantages and share benefits to achieve the effective integration and linkage of the resources in the entire value chain. Consequently, they can achieve agile manufacturing to form a dynamic virtual organization with a specific target.

\section{Crossed Network Externality}

Internet platform economy has the feature of network externality. Network externality usually refers to that there are two types of users on the Internet platform and the scale of a type of users will significantly affect the utility or value of the platform of the other type of users. For example, the more online shopkeepers are on the Taobao Internet platform, the more the goods they provide. Therefore, the competition between the same products will be more 
intense and the price will be more low, so that the shop will have greater attraction and value for online shopping users. The prosperity of the Internet platform depends on the harmonious development between the two types of users. If there are more users who participate in the platform, other users will be more pleased to join in the platform. To this end, the larger the scale of the users becomes, the more obvious the brand effect is. Besides, the platform can also receive a huge return[6]. Therefore, when users choose a platform, they not only focuses on the development of the platform, but also pays attention to the platform users. Internet platform needs to simultaneously balance the needs of the two types of users and provide different services and pricing strategies according to the scale and need of the two types of users.

\section{The Integration of the Basic Services and Value-added services and the Combination of the Free and Paid Services}

The Internet platform usually provides two kinds of services: basic services and value-added services. Basic services are generally free and value-added services are charged. Basic services only include the most basic services and value-added services meet users' extensive and various needs. For example, the search platform provides the simple search service. A company can search other businesses or be searched by other enterprises. This is a basic service. However, if the company wants to rank in the top search results, they need to pay competitive ranking fee to the platform. The competitive ranking service is a value-added service. Due to the externality of the Internet platform, to improve the experience of free users and retain these users is an important marketing strategy for the platform. With the intensification of the competition between Internet platforms, the scale of free user resources has become the main indicator to assess the competitiveness of the platform and it is a difficult thing for platforms to develop and retain customers. Many platforms fully consider the user experience from product design, research, development, application and customer service.

\section{Aggregation, Integrity and Driving Force}

Internet platform has a strong aggregation, which is reflected in the following things: first, the platform gathers a variety of subjects. For example, the trading platform includes buyers, sellers and service providers; the social platform brings individuals, various communities and advertisers together; the industrial cloud platform converges a variety of small and medium enterprises and service providers. Second, the Internet platform collects massive amounts of information. For instant,the trading platform brings a variety of product information, price information and business dynamic information together; social platforms include personal information, friends information and dynamic information in the friends 
circle. Third, the Internet platform brings various relationships between subjects and social resources, such as partnership, competition relation and friendship. Internet platform can integrate relationships between subjects and reconstruct the value chain. Subjects on the Internet platform can communicate with each other directly and search for the best cooperation paths and partners to reconstruct relations and the value chain.

\section{Innovation is the Driving Force for the Appearance and Development of the Internet Platform}

Innovation is the driving force for the appearance and sustainable development of the Internet platform. Back in the early days of the Internet, Sina, Sohu, NetEase, TOM, CDC and 8848 were outstanding websites in the Internet platform economy in China. However, with the user needs and environment changing, some platforms does not advance with the times, and they are regressive or even eliminated by the market[7]. Only Internet platforms make innovation continuously, keep abreast of cutting-edge technology and meet users' needs, can they survive in the forefront of the platform economy. Innovation helps Internet platform companies to attract more users and bring more revenues.

\section{Sharing}

Another major feature of the Internet platform economy is that it has a sharing business model. Sharing Internet platform is to provide a platform for users to share resources, goods or services. Sharing Internet platform absorbs a large number of dispersed resources and integrates them orderly to provide them to users who need these resources. Sharing makes the flow of resources more rational and improves the use value and efficiency of resources, which saves the cost in the society. For example, Uber is an Internet platform who provides carsharing service. It integrates unused cars and idle car owners, and provides a platform, so that car owners can take advantage of free time to provide special car or carpool services. WeChat is also a sharing platform where users can share their emotions in personal life, interesting views and wonderful articles in their friend circle.

\section{References}

[1] Gao Xiaoping. A Study on the Competition Model of the Internet Enterprises from the Perspective of the Platform Economy. Cooperative Economy and Science, (24), pp.71-73, 2016. 
[2] Gao Xiaoping. A Research of the Enterprise Competition Strategies Based on the Platform Economy Model. Modern Economic Information, (19), pp.283-285, 2016.

[3] Yang Qian, Zhang Man and Ye Zhijuan. A Study on the Platform Economy and Fragmentation of the Division of Labor under the Background of the " Internet +" . Chinese and Foreign Entrepreneurs, (23), pp.34-36, 2016.

[4] Lin Xiang, Chi Wei. The Platform Economy Paradox: the Independent Broadcasting Strategies of Traditional TV Media in the Internet Environment. Press Circles, (21), pp.30-34, 2014.

[5] Yang Kai, Liu Zhaocai. A Study on Automobiles from the Perspective of the Internet Platform Economy. Auto Industry Research, (08), pp.33-35, 2014.

[6] Guo Quanzhong, Guo Fengjuan. A Study on the Platform Economy and the Change of Media Business Model .Youth Journalist, (09), pp.16-18, 2013.

[7] Sun Guoliang. An Analysis of the Development of the Internet Economy Platform. Modern Economic Information, (04), pp.3-4, 2008. 